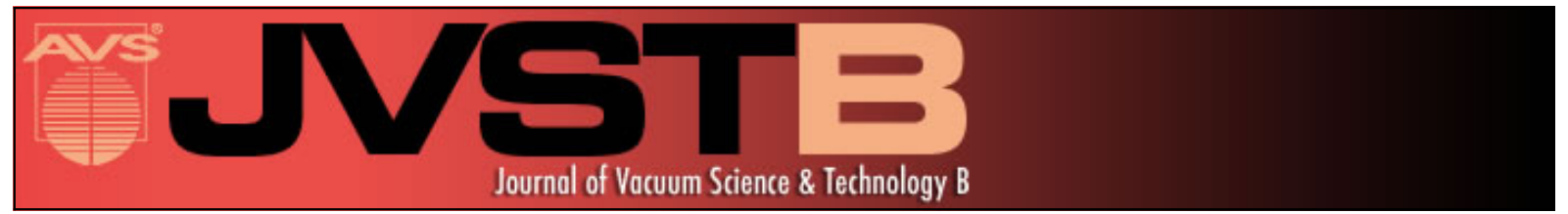

\title{
Atomic layer deposition of Ta-based thin films: Reactions of alkylamide precursor with various reactants
}

W. J. Maeng, Sang-Joon Park, and H. Kim

Citation: Journal of Vacuum Science \& Technology B 24, 2276 (2006); doi: 10.1116/1.2345205

View online: http://dx.doi.org/10.1116/1.2345205

View Table of Contents: http://scitation.aip.org/content/avs/journal/jvstb/24/5?ver=pdfcov

Published by the AVS: Science \& Technology of Materials, Interfaces, and Processing

\section{Articles you may be interested in}

Microstructure analysis of plasma enhanced atomic layer deposition-grown mixed-phase RuTaN barrier for seedless copper electrodeposition

J. Vac. Sci. Technol. A 30, 020604 (2012); 10.1116/1.3684597

Reaction mechanisms of atomic layer deposition of $\mathrm{TaN} x$ from $\mathrm{Ta}(\mathrm{NMe} 2) 5$ precursor and $\mathrm{H} 2$-based plasmas J. Vac. Sci. Technol. A 30, 01A101 (2012); 10.1116/1.3625565

Nucleation delay in atomic layer deposition on a thin organic layer and the role of reaction thermochemistry J. Vac. Sci. Technol. A 30, 01A102 (2012); 10.1116/1.3625564

Structures of ultra-thin atomic-layer-deposited TaN x films

J. Appl. Phys. 95, 6167 (2004); 10.1063/1.1711176

The physical properties of cubic plasma-enhanced atomic layer deposition TaN films

J. Appl. Phys. 95, 5848 (2004); 10.1063/1.1704863

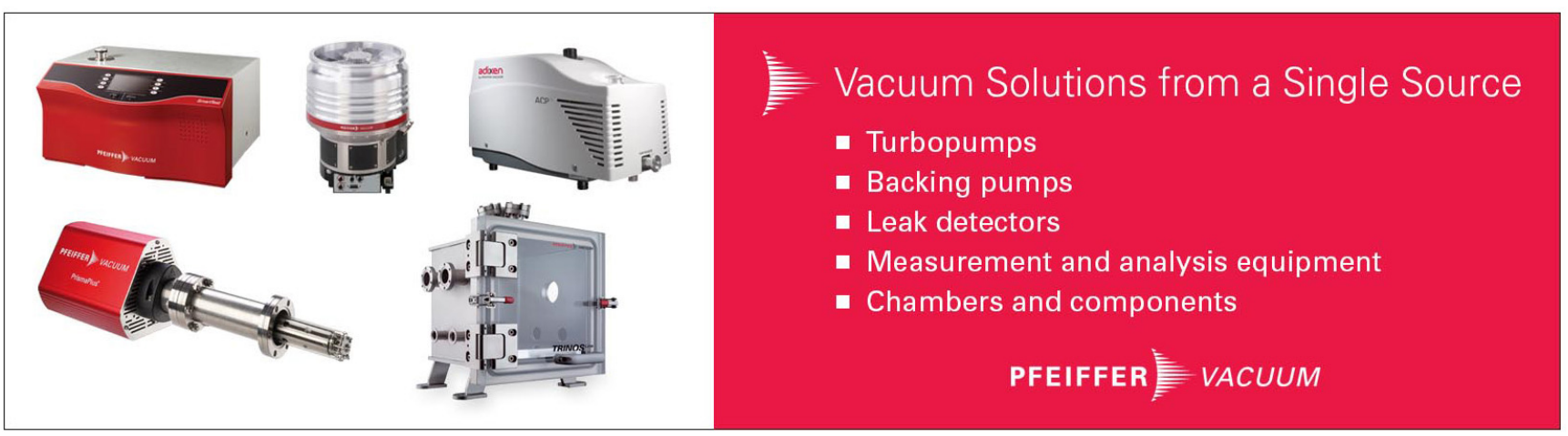




\title{
Atomic layer deposition of Ta-based thin films: Reactions of alkylamide precursor with various reactants
}

\author{
W. J. Maeng, Sang-Joon Park, and H. Kim ${ }^{\text {a) }}$ \\ Department of Materials Science and Engineering, Pohang University of Science and Technology, \\ Pohang 790-784, Korea
}

(Received 31 May 2006; accepted 1 August 2006; published 18 September 2006)

\begin{abstract}
The growth mechanisms and film properties of atomic layer deposition (ALD) Ta-based thin films were investigated from alkylamide precursor $\left[\mathrm{Ta}\left(\mathrm{NMe}_{2}\right)_{5}\right.$, (PDMAT)]. The reactions of PDMAT with various reactants including water, $\mathrm{NH}_{3}$, oxygen, and hydrogen plasma were studied and the resulting film properties were investigated by various analysis techniques. For TaN ALD from $\mathrm{NH}_{3}$ and $\mathrm{H}$ plasma, the films were contaminated by considerable amount of carbon, while the $\mathrm{Ta}_{2} \mathrm{O}_{5}$ deposited from water and O plasma were quite pure. Also, nitrogen was incorporated for ALD from PDMAT and $\mathrm{H}$ plasma, while no nitrogen incorporation was observed for O-plasma based plasma enhanced-ALD of $\mathrm{Ta}_{2} \mathrm{O}_{5}$ except at high deposition temperature over $300{ }^{\circ} \mathrm{C}$. The results were comparatively discussed focusing on the differences in growth mechanism depending on reactants. (C) 2006 American Vacuum Society. [DOI: 10.1116/1.2345205]
\end{abstract}

\section{INTRODUCTION}

Ta-based thin films have been widely investigated for many important applications in modern nanoscale semiconductor device fabrications. For example, TaN is a representative diffusion barrier for current $\mathrm{Cu}$ interconnect technology and one of the important candidates for metal gate in complementary metal-oxide-semiconductor (CMOS) device. ${ }^{1,2}$ Also, tantalum oxide $\left(\mathrm{Ta}_{2} \mathrm{O}_{5}\right)$ thin films have been widely studied as a capacitor dielectric material in dynamic random access memory as well as a gate dielectric for nanoscale CMOS devices. ${ }^{3,4}$ Due to the importance in applications, various thin film deposition techniques including chemical vapor deposition $^{5,6}$ (CVD) and physical vapor deposition ${ }^{7}$ have been employed to deposit Ta-based materials.

However, with scaling down of the integrated devices, the need for a deposition technique to produce highly conformal films at nanoscale is becoming tremendous. Regarding this, atomic layer deposition (ALD) is being considered as a promising deposition technique due to many benefits including high conformality, high film qualities at low growth temperature, uniformity over large areas, and controllability in nanoscale thickness. ${ }^{8,9}$ One of the critical issues for successful ALD process is the proper selection of precursor and reactant. For ALD of Ta-based materials, several different Ta precursors including halides ${ }^{10-12}$ and metalorganic precursors such as ethoxide ${ }^{10}$ and alklamide have been studied. ${ }^{13}$ For thermal $\mathrm{ALD}, \mathrm{NH}_{3}$ is the typical reactant for nitride while water is the one for oxide. More recently, plasma enhanced ALD (PE-ALD) has been developed for obtaining films with better quality at lower deposition temperature, mainly due to the high reactivity of the radicals and ions. ${ }^{14}$

Among various precursors for ALD, alkylamide precursors have attracted great interests since they have high vapor pressures and $\mathrm{Cl}$ - and $\mathrm{O}$-free ligands. Moreover, ALD from

${ }^{a)}$ Electronic mail: hyungjun@ postech.ac.kr alkyamide is processed at relatively lower growth temperatures producing noncorrosive products. Especially, alkylamide precursor such as pentakis-(dimethylamino)Ta (PDMAT) or tetrakis-(dimethylamino)Ti (TDMAT) has been extensively studied for deposition of TaN or TiN. ${ }^{15,16}$ For example, we reported that PE-ALD of TaN from PDMAT and hydrogen plasma produced good quality TaN, which shows very robust characteristics as a diffusion barrier for $\mathrm{Cu}$ interconnect. ${ }^{15}$ However, the alkylamide precursors have rarely been used for deposition of Ta or Ti oxide, ${ }^{13,17}$ while they have been major precursors for ALD of other high $k$ oxides including $\mathrm{ZrO}_{2}$ and $\mathrm{HfO}_{2}$. Also, it is interesting to note that ALD of $\mathrm{Hf}$ and $\mathrm{Zr}$ nitride thin films has been rarely reported. $^{18}$

In this study, we have performed comparative study on ALD of Ta-based thin films, TaN and $\mathrm{Ta}_{2} \mathrm{O}_{5}$, from PDMAT and various reactants including water, $\mathrm{NH}_{3}$, and $\mathrm{O}$ and $\mathrm{H}$ plasma. As far as we know, there has been no detailed comparative study between oxide and nitride ALD process from the same alkylamide precursor. TaN thin films were deposited by the reaction between PDMAT and $\mathrm{NH}_{3}$ or $\mathrm{H}$ plasma, while $\mathrm{Ta}_{2} \mathrm{O}_{5}$ thin films by water or $\mathrm{O}$ plasma. The growth characteristics were studied as a function of key growth parameters including precursor and reactant exposure times and growth temperatures. Chemical and microstructural properties were compared using various analysis techniques including X-ray photoelectron spectroscopy (XPS), Rutherford backscattering (RBS), and X-ray diffraction (XRD). Based upon the results, the differences in growth mechanisms and the implications for film properties are discussed.

\section{EXPERIMENTAL PROCEDURES}

The schematic of PE-ALD system utilized in this study is shown Fig. 1. Sample size as large as 8 in. can be loaded and the chamber is pumped by turbo molecular pump with a base pressure of $10^{-7}$ Torr. The PDMAT (powder) was contained in a bubbler and its temperature was kept at $65^{\circ} \mathrm{C}$ to gener- 


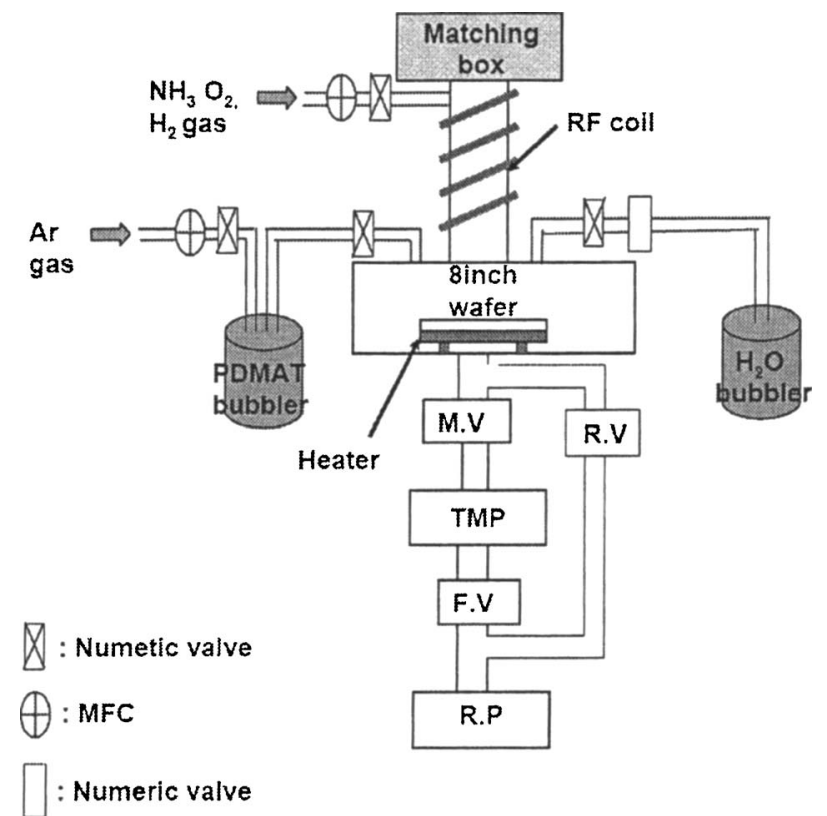

FIG. 1. Schematic diagram for the PE-ALD system.

ate high enough vapor pressure. To prevent possible condensation of the precursor inside the delivery lines, the temperature of all the lines were kept at slightly higher temperature than that of bubbler. Ar was used as carrier and purging gas and the flow was controlled by mass flow controller (MFC) upstream to the main chamber. The flow rates were set as $50 \mathrm{sccm}$ for carrier gas and $75 \mathrm{sccm}$ for purging gas, respectively. Also, the flows of $\mathrm{NH}_{3}, \mathrm{H}_{2}$, and $\mathrm{O}_{2}$ were all controlled by MFC while the flow of water vapor was controlled by leak valve. The flow rates of $\mathrm{O}_{2}, \mathrm{NH}_{3}$, and $\mathrm{H}_{2}$ were set as 30 , 20 , and $20 \mathrm{sccm}$, respectively. With these flow, the chamber pressure during reactant exposure increased to about 10 mTorr at standard growth condition. The water flow was controlled by leak valve by monitoring the pressure with capacitance manometer to be constant at $0.5 \mathrm{mTorr}$. The temperature of the water was maintained constant at room temperature by immersing the bubbler in silicon oil. For PEALD, oxygen or hydrogen plasma was generated by a radio frequency remote type inductively coupled plasma generator, which is composed of a quartz tube connected to the sample chamber with auto matching box. For oxygen and hydrogen, the plasma power was set at 300 and $500 \mathrm{~W}$, respectively. The deposition cycle consists of the following steps: exposure of the substrate to PDMAT for a set time $t_{s}$, purging of the chamber, exposure of reactant for a set time $t_{r}$, and purging.

The films were deposited on $\mathrm{Si}(100)$ substrates, which were cleaned by HF dipping without further cleaning step. For $\mathrm{Ta}_{2} \mathrm{O}_{5}$, the thickness was routinely determined by Ellipsometer (Rudolph Auto ELII). Additional film thickness measurements were done by RBS or scanning electron microscopy. The film composition and binding structure were determined by RBS and XPS. Microstructure of the films was determined by XRD.

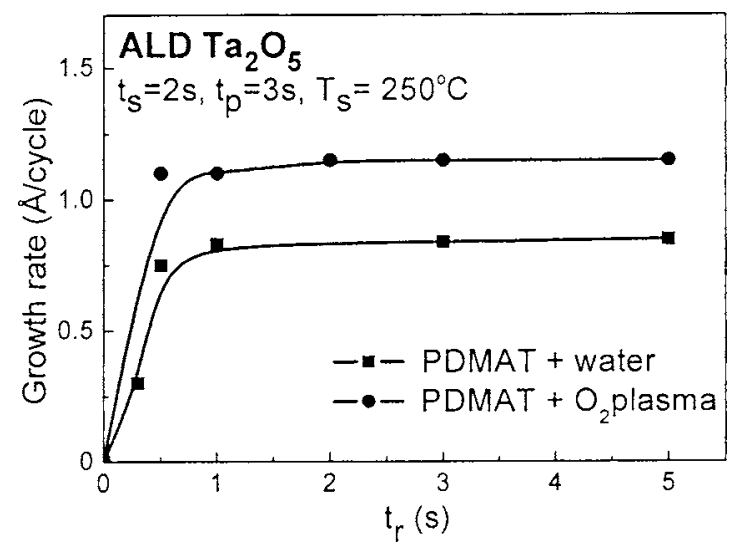

FIG. 2. Growth rate of thermal and PE-ALD $\mathrm{Ta}_{2} \mathrm{O}_{5}$ as a function of water exposure time $\left(t_{r}\right)$ on $\mathrm{Si}(100)$ substrate at $T_{s}=250{ }^{\circ} \mathrm{C}$.

\section{EXPERIMENTAL RESULTS}

We have deposited $\mathrm{Ta}_{2} \mathrm{O}_{5}$ by thermal and PE-ALD using water and oxygen plasma as a reactant, respectively. The initial results on the growth characteristics and film properties can be found in our recent report. ${ }^{19}$ For both thermal and PE-ALD of $\mathrm{Ta}_{2} \mathrm{O}_{5}$, the growth rates rapidly increase and saturate at $t_{s}>1 \mathrm{~s}$. The saturation growth rate of thermal ALD is $0.85 \AA$ /cycle and that of PE-ALD is $1.2 \AA /$ cycle at typical growth temperature of $250{ }^{\circ} \mathrm{C}$. (Fig. 2) Thus, compared to thermal ALD, lower temperature growth is possible with higher growth rate by PE-ALD. The higher growth rate of PE-ALD is probably due to the highly reactive plasma radicals, resulting in more favorable surface reactions of the precursor. ${ }^{14}$ Figure 2 also shows that the growth rate saturates well at long exposure time, which satisfies the basic requirement of ALD process. This is in contrast to the $\mathrm{TiO}_{2}$ ALD from TDMAT showing poor saturation in growth rate. ${ }^{19}$ The growth rate change with growth temperature is divided into three regions, as shown in Fig. 3 for PE-ALD $\mathrm{Ta}_{2} \mathrm{O}_{5}$. At the middle growth temperature region, the growth rate is almost constant, corresponding to so-called "process window." PE-ALD has shown broader temperature range

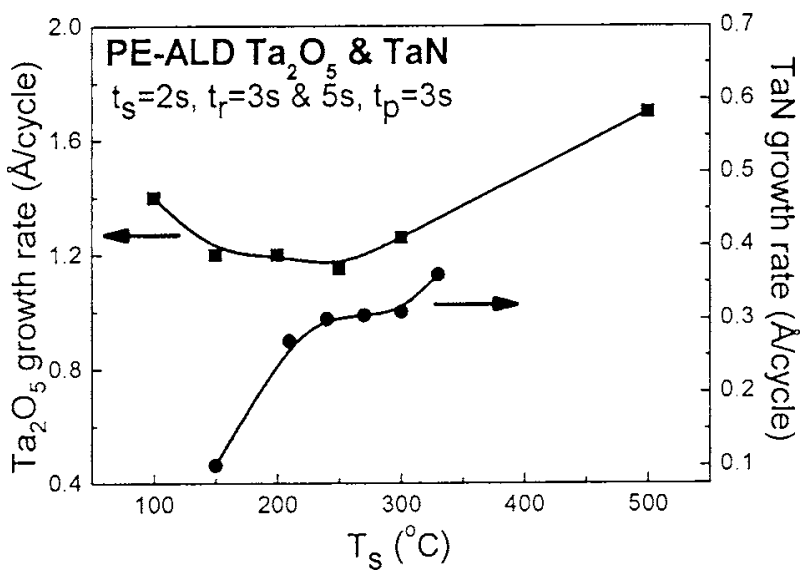

FIG. 3. Growth rate of PE-ALD $\mathrm{Ta}_{2} \mathrm{O}_{5}$ and TaN as a function of growth temperature on $\mathrm{Si}(100)$ substrates. 


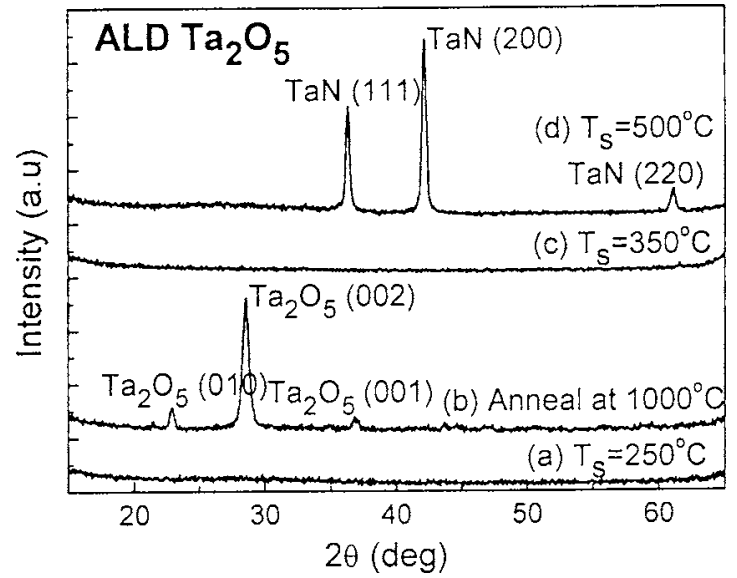

FIG. 4. X-ray diffraction spectra of the thermal ALD $\mathrm{Ta}_{2} \mathrm{O}_{5}$ films deposited at 250,350 , and $500{ }^{\circ} \mathrm{C}$ on $\mathrm{Si}(100)$ substrate. Also shown is the XRD spectrum of the film deposited at $250^{\circ} \mathrm{C}$ followed by annealing at $1000{ }^{\circ} \mathrm{C}$.

than thermal ALD (data not shown) due to the presence of radicals (mostly oxygen atoms in this case) leading to higher reactivity. This region is $200-250{ }^{\circ} \mathrm{C}$ for thermal ALD and $150-250{ }^{\circ} \mathrm{C}$ for PE-ALD. At higher temperature region, $T_{s}$ $>250{ }^{\circ} \mathrm{C}$, the growth rate rapidly increases, up to $1.6 \AA /$ cycle at $500{ }^{\circ} \mathrm{C}$, which can be attributed to the thermal decomposition of PDMAT, resulting in the disturbance of self-saturation adsorption. Thermal decomposition of PDMAT was reported to produce $\mathrm{Ta}_{2} \mathrm{O}_{5}$ with large $\mathrm{C}$ contamination during CVD of $\mathrm{Ta}_{2} \mathrm{O}_{5}$ at $400{ }^{\circ} \mathrm{C} .{ }^{20}$ Meanwhile, at low growth temperature, $T_{s}<200{ }^{\circ} \mathrm{C}$, the growth rate increases again with decreasing temperature.

The microstructure of thermal ALD $\mathrm{Ta}_{2} \mathrm{O}_{5}$ thin films was investigated by XRD. As Fig. 4 shows, we cannot observe any diffraction peak, indicating that the film has amorphous microstructure at typical growth temperature of $250{ }^{\circ} \mathrm{C}$. Similarly, amorphous structure of ALD $\mathrm{Ta}_{2} \mathrm{O}_{5}$ was reported for ALD from ethoxide precursors. ${ }^{21}$ After annealing at $1000{ }^{\circ} \mathrm{C}$ in vacuum ambient for $20 \mathrm{~min}$, however, clear orthorhombic $\mathrm{Ta}_{2} \mathrm{O}_{5}$ diffraction peaks are observed. $\mathrm{Ta}_{2} \mathrm{O}_{5}$ recrystallization is reported to start between 600 and $800{ }^{\circ} \mathrm{C}$ resulting in orthorhombic $\beta-\mathrm{Ta}_{2} \mathrm{O}_{5}$ phase. ${ }^{22}$ While hexagonal $\delta-\mathrm{Ta}_{2} \mathrm{O}_{5}$ was reported at growth temperature of $350{ }^{\circ} \mathrm{C}$ for $\mathrm{Ta}_{2} \mathrm{O}_{5}$ ALD from $\mathrm{TaCl}_{5}$ and water, ${ }^{23}$ the ALD $\mathrm{Ta}_{2} \mathrm{O}_{5}$ film in this study remained amorphous up to $T_{s}=350{ }^{\circ} \mathrm{C}$. However, the XRD spectrum of as-deposited film grown at $500{ }^{\circ} \mathrm{C}$ shows clear cubic TaN peaks. We can infer that large nitrogen incorporation occurs at high growth temperature, partially forming TaN cubic phase. ${ }^{24}$ However, since the XRD peak positions of $\mathrm{TaC}$ phase are very similar to those of $\mathrm{TaN}$, we cannot exclude the possibility of $\mathrm{TaC}$ phase formation. Meanwhile, no $\mathrm{Ta}_{2} \mathrm{O}_{5}$ related peak was observed, indicating that oxide phase remains amorphous up to $500{ }^{\circ} \mathrm{C}$. The same results were obtained for $\mathrm{Ta}_{2} \mathrm{O}_{5}$ PE-ALD (data not shown).

The chemical composition and bonding structure of the films were analyzed by XPS and RBS. Figure 5 shows the XPS spectra of thermal ALD $\mathrm{Ta}_{2} \mathrm{O}_{5}$ films grown at 150, 250, and $500{ }^{\circ} \mathrm{C}$. Similar spectra were obtained for PE-ALD at comparable growth temperature ranges. For both thermal and
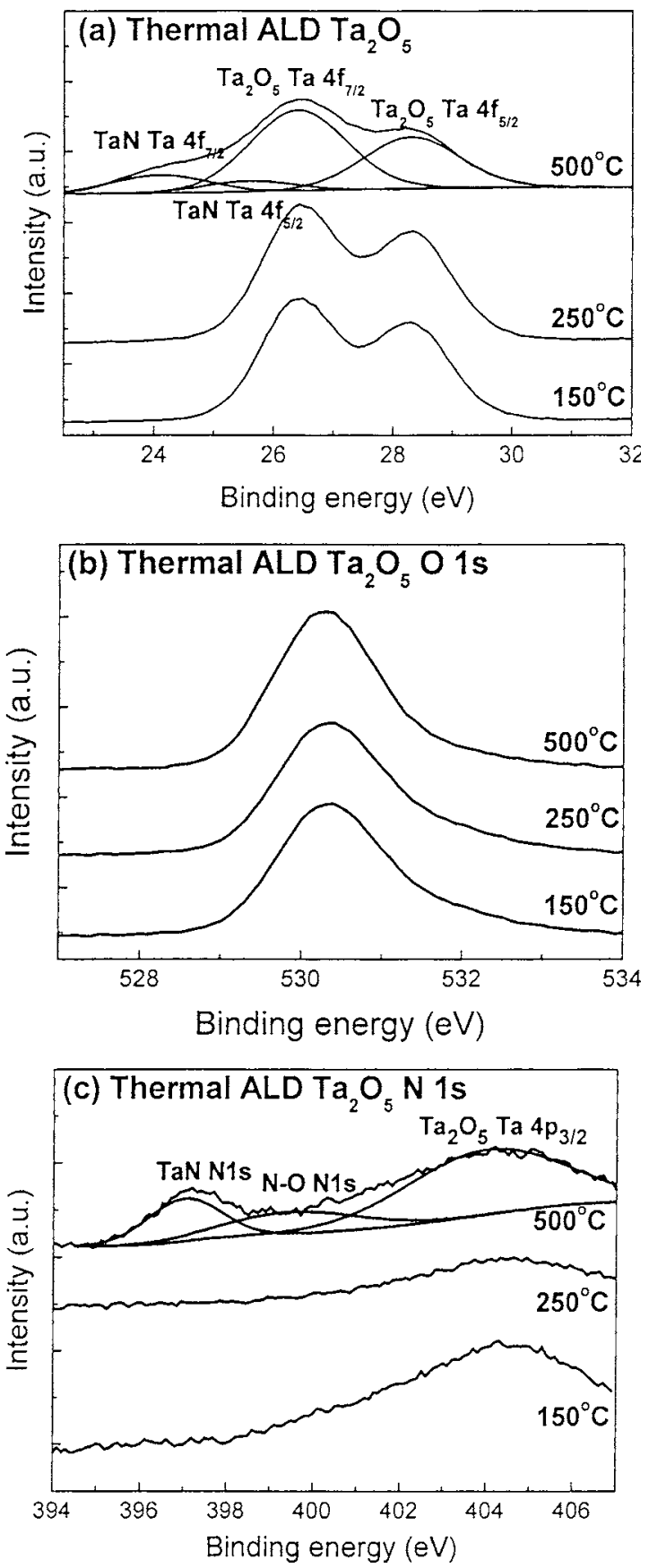

FIG. 5. XPS spectra of (a) Ta $4 f$, (b) O $1 s$, and (c) $\mathrm{N} 1 s$ for thermal ALD $\mathrm{Ta}_{2} \mathrm{O}_{5}$ from PDMAT reacting with water at 150,250 , and $500{ }^{\circ} \mathrm{C}$.

PE-ALD $\mathrm{Ta}_{2} \mathrm{O}_{5}$ grown at 150 and $250{ }^{\circ} \mathrm{C}$, only the standard Ta $4 f_{7 / 2}$ peak (located at $26.5 \mathrm{eV}$ ) and Ta $4 f_{5 / 2}$ peak (located at $28.4 \mathrm{eV}$ ) of Ta-O bond are observed. No other Ta-related peak such as $\mathrm{Ta}-\mathrm{N}$ or metallic $\mathrm{Ta}$ or other impurity-related peak is observed, indicating that the deposited $\mathrm{Ta}_{2} \mathrm{O}_{5}$ films are very pure $(\mathrm{C}, \mathrm{N}<1 \%)$. For more information of composition, impurity contents, and film density, RBS analysis was performed. Oxygen resonance RBS spectrum of PE-ALD $\mathrm{Ta}_{2} \mathrm{O}_{5}$ deposited at $250{ }^{\circ} \mathrm{C}$ with $18 \mathrm{~nm}$ thickness is shown in Fig. 6. Carbon and nitrogen resonance RBS spectrum did not show any carbon or nitrogen related feature for films depos- 


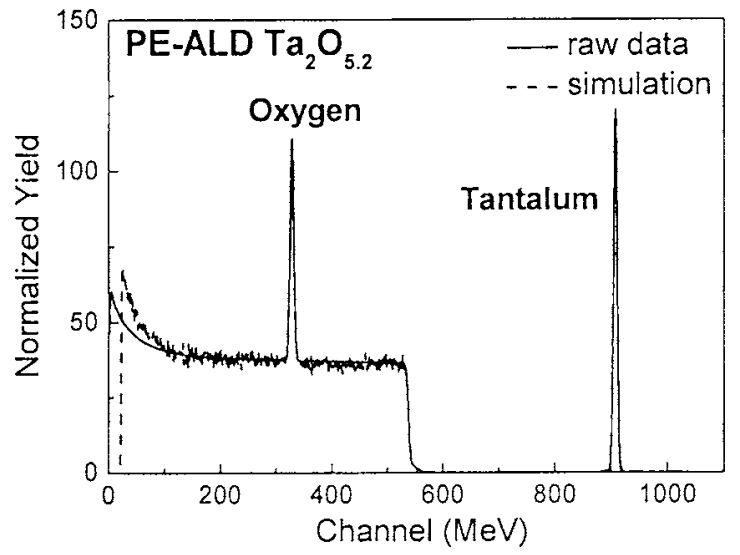

FIG. 6. RBS data for PE-ALD $\mathrm{Ta}_{2} \mathrm{O}_{5}$ film with $18 \mathrm{~nm}$ thickness. The growth temperature was $250{ }^{\circ} \mathrm{C}$.

ited at $T_{s}<300{ }^{\circ} \mathrm{C}$. The Ta: $\mathrm{O}$ ratio in the film was estimated to be 2:5.2 $( \pm 0.1)$. Also, the density of PE-ALD $\mathrm{Ta}_{2} \mathrm{O}_{5}$ was evaluated to be $94 \%$ of bulk value. Higher density of PE-ALD oxide than that of thermal ALD is partly attributed to the increase in the reactivity of the oxidizer. ${ }^{25}$

However, the XPS spectrum of $\mathrm{Ta}_{2} \mathrm{O}_{5}$ film deposited at high growth temperature shows significantly different aspects. The Ta XPS peaks of $\mathrm{Ta}_{2} \mathrm{O}_{5}$ film grown at $T_{s}$ $=500{ }^{\circ} \mathrm{C}$ are much broader than those of films grown at lower growth temperatures. By the deconvolution of the peaks, we have found that additional peaks at 24.1 and $25.9 \mathrm{eV}$ exist besides Ta-O peaks mentioned earlier. These peaks correspond to Ta peaks from TaN phase. ${ }^{26,27}$ Thus, at high growth temperature, TaN phase is formed by the incorporation of nitrogen from the ligands of PDMAT, which agrees with XRD results shown in Fig. 4. More obvious evidence for nitrogen incorporation is the emergence of $\mathrm{N} 1 s$ peak at $396.6 \mathrm{eV}$ shown in Fig. 4(c). Besides Ta $4 p_{3 / 2}$ peak of Ta-O bonding at $404.2 \mathrm{eV}$, which is also observed for films deposited at low temperatures, additional $\mathrm{N}-\mathrm{O}$ peak is observed at about $400 \mathrm{eV}$. Although quantitative determination of nitrogen in the films by XPS is limited, the incorporated $\mathrm{N}$ content in the films is approximately 5 at. \%. However, even for sample deposited at $500{ }^{\circ} \mathrm{C}$, little carbonrelated peak was observed. Combining XPS results with XRD spectra, we can conclude that the ALD $\mathrm{Ta}_{2} \mathrm{O}_{5}$ film prepared at $500{ }^{\circ} \mathrm{C}$ is composed of cubic TaN grains imbedded in $\mathrm{Ta}_{2} \mathrm{O}_{5}$ amorphous matrix.

Next, TaN films were deposited by thermal and PE-ALD using $\mathrm{NH}_{3}$ and $\mathrm{H}$ plasma as a reactant, respectively. Thermal ALD from PDMAT and $\mathrm{NH}_{3}$ is reported to produce films containing considerable carbon impurity with high nitrogen concentration. ${ }^{28}$ XRD results (data not shown) indicate that the thermal ALD TaN $\mathrm{T}_{x}$ film is amorphous with immeasurable high resistivity. RBS results indicate that the film has $\mathrm{N} / \mathrm{Ta}$ ratio close to that of $\mathrm{Ta}_{3} \mathrm{~N}_{5}$ with significant carbon concentration. XPS spectra of thermal ALD TaN films on $\mathrm{Si}(100)$ grown at $T_{s}=220{ }^{\circ} \mathrm{C}$ are shown in Fig. 7. Even after in situ cleaning right before analysis, significant Ta peaks from $\mathrm{Ta}-\mathrm{O}$ bonding is observed after deconvolution of the spec-
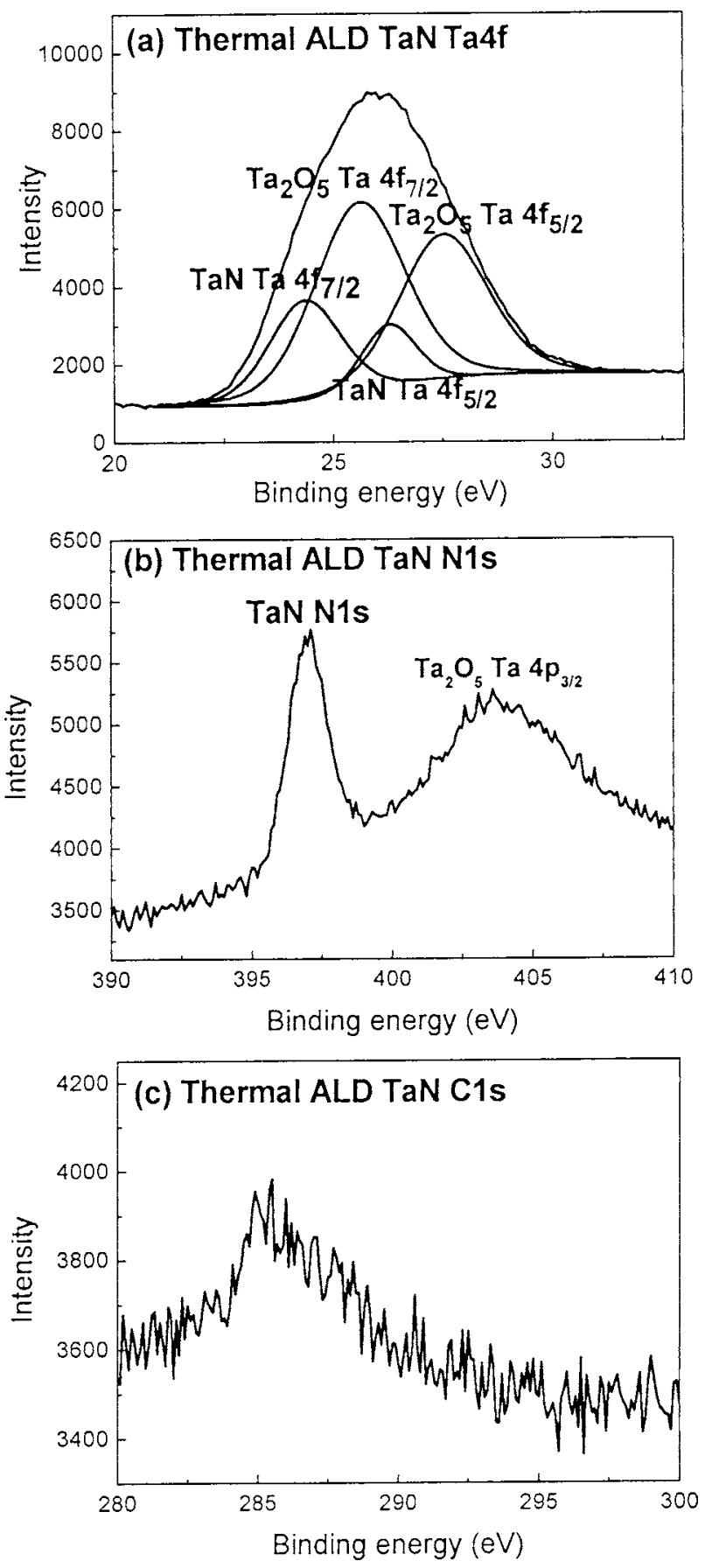

FIG. 7. XPS spectra of (a) Ta $4 f$, (b) O $1 s$, and (c) $\mathrm{N} 1 s$ for thermal ALD $\mathrm{TaN}_{x}$ from PDMAT reacting with $\mathrm{NH}_{3}$.

trum [Fig. 7(a)]. This is probably due to the post deposition oxidation of $\mathrm{TaN}_{x}$ film, since the film was exposed to air for several days before the XPS analysis. Similarly, large postdeposition oxidation related XPS peaks were reported for PE-CVD of TaN from PDMAT and H plasma. ${ }^{29}$ Figure 7(c) shows significant $\mathrm{C}$ incorporation from PDMAT, which is contrast to $\mathrm{Ta}_{2} \mathrm{O}_{5}$ ALD, where no carbon XPS peak is observed. From XPS results, the carbon content was estimated to be 9 at. \%. In contrast, H-plasma based PE-ALD TaN has low resistivity with well resolved cubic TaN XRD peaks. 
RBS reveals that the N/Ta ratio was close to 0.8 with carbon concentration as high as 15 at. \% at typical growth conditions. More detailed results can be found in our previous report. $^{15}$

The comparison of growth rate change depending on the growth temperature for PE-ALD of TaN (closed circle) and $\mathrm{Ta}_{2} \mathrm{O}_{5}$ (closed square) is shown in Fig. 3. For both cases, the growth rates remain almost constant between 200 and $275^{\circ} \mathrm{C}$, while they increase rapidly at higher growth temperature region. However, the growth rates at this typical ALD conditions are quite different each other. The saturation growth rate of PE-ALD $\mathrm{Ta}_{2} \mathrm{O}_{5}$ is about $1.2 \AA / \mathrm{s}$ as described early, while that of PE-ALD TaN is much smaller, about $0.35 \AA / s$. Besides, the growth rate increases with decreasing growth temperature for PE-ALD $\mathrm{Ta}_{2} \mathrm{O}_{5}$, but that for PE-ALD TaN shows opposite trend. Analogous results were observed for thermal ALD of $\mathrm{Ta}_{2} \mathrm{O}_{5}$ and $\mathrm{TaN}_{x}$ ALD from water and $\mathrm{NH}_{3}$.

\section{DISCUSSION}

The noticeable difference in growth characteristics between Ta oxide and nitride ALD from PDMAT is at the lower growth temperature region. In other words, the growth rate of ALD $\mathrm{Ta}_{2} \mathrm{O}_{5}$ from water and $\mathrm{O}$ plasma increases with decreasing growth temperature at $T_{s}<200{ }^{\circ} \mathrm{C}$, while the growth rate change with growth temperature of TaN ALD from $\mathrm{NH}_{3}$ and $\mathrm{H}$ plasma shows the opposite trend. The similar behavior to our $\mathrm{Ta}_{2} \mathrm{O}_{5}$ ALD results was observed for other transition metal oxide ALD from alkylamide precursors with water or oxygen plasma. ${ }^{30-32}$ Also, ALD $\mathrm{Ta}_{2} \mathrm{O}_{5}$ from $\mathrm{TaCl}_{5}$ and water was reported to have similar behavior. ${ }^{23}$ One of the plausible explanations proposed for this phenomenon is that the concentration of surface $\mathrm{OH}$ groups becomes higher with decreasing growth temperature at low growth temperature region, which leads to more number of active sites resulting in a higher growth rate. ${ }^{33,34}$ This explanation could be generally applied for thermal ALD of oxide using water as a reactant. However, for PE-ALD using oxygen plasma as a reactant, the formation of $\mathrm{OH}$ terminated surface has not been clearly identified yet. In a more recent report, optical emission spectroscopy analysis of oxygen plasma during PE-ALD indicated the presence of hydrogen radicals, which could results in $\mathrm{OH}$ terminated surface by reaction of oxygen radicals with hydrogen likely to be originated from precursors. $^{35}$ Thus, the same explanation would be applicable for PE-ALD of oxides. However, for ALD of TaN, the OHsurface concentration does not play a critical role in determining growth rate. In this case, the growth rate decreases with decreasing temperature, simply due to less surface reaction at lower growth temperatures.

Another point to be discussed is the impurity incorporation for ALD of Ta-based materials. To make the discussion simpler, we will focus on the comparison between PDMAT reaction with $\mathrm{O}$ plasma and $\mathrm{H}$ plasma. But analogous discussion can be applied for thermal ALD of Ta oxide from water and Ta nitride from $\mathrm{NH}_{3}$. As we mentioned in the experimental section, considerable amount of $\mathrm{N}$ and $\mathrm{C}$ incorporation

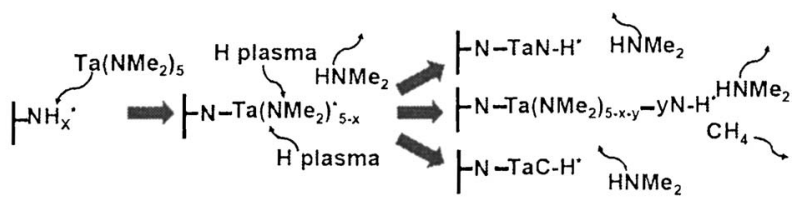

(a) PDMAT $+\mathrm{H}$ plasma

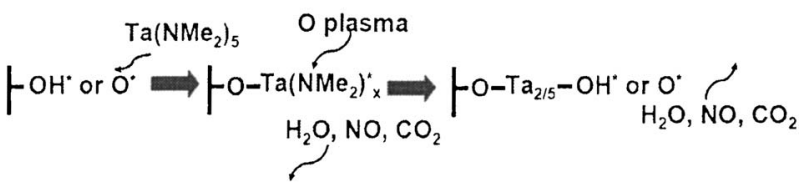

(b) PDMAT + O plasma

FIG. 8. Illustrations showing the reaction schemes for (a) $\mathrm{TaN}$ and (b) $\mathrm{Ta}_{2} \mathrm{O}_{5}$ PE-ALD.

occurs during PE-ALD of TaN. For example, the N/Ta ratio was 0.8 with high concentration of $\mathrm{C}$ as large as 15 at. \%. This indicates that the $\mathrm{N}$ from the ligands should be broken by $\mathrm{H}$ plasma to produce $\mathrm{N}$ and $\mathrm{C}$ incorporation. For nitride ALD from alkylamide precursors, it is generally observed that the purity of the film is relatively low. For example, low density and high $\mathrm{C}$ incorporation during TiN ALD from TDMAT and $\mathrm{NH}_{3}$ have been problematic. ${ }^{16}$ But PDMAT reacting with oxygen plasma does not produce any detectable incorporation of carbon or nitrogen. The relatively pure film deposition of transition metal oxide film from alkylamide precursors are common to other material systems, including $\mathrm{HfO}_{2}$ and $\mathrm{ZrO}_{2}{ }^{31,32}$

Based upon these results, we infer that there are distinguished differences in ALD reaction mechanism for nitride and oxide from PDMAT (Fig. 8). In the PDMAT+H plasma reaction, after first step when the surface is saturated by the adsorbed PDMAT molecules, the surface is exposed to hydrogen plasma. At this step, ideally all of the $\mathrm{NMe}_{2}$ is removed by forming $\mathrm{H}\left(\mathrm{NMe}_{2}\right)$. However, since the current results indicate that $\mathrm{TaN}$, not $\mathrm{Ta}$, is formed, at least one out of five ligands should be broken to form a Ta-N bond with a $\mathrm{N} / \mathrm{Ta}$ ratio of 0.8 in the film. If no dimethylamino species is broken, Ta metal, not TaN, would have been deposited. After this step, the surface may be composed of Ta atoms adsorbed on surface with $\mathrm{NH}$ or $\mathrm{H}$ bonded to Ta. By the successive reaction with PDMAT, $\mathrm{H}$ would react with alkylamide precursor while some of the $\mathrm{N}$ atoms are again incorporated to form TaN. Also, some of the ligands should be broken to incorporate $\mathrm{C}$ atoms in the film, since significant carbon incorporation was observed from chemical analysis.

For PDMAT reaction with $\mathrm{O}$ plasma during $\mathrm{Ta}_{2} \mathrm{O}_{5}$ PEALD, although no intended $\mathrm{H}$ dosing is present, the $\mathrm{OH}$ terminated surface is formed as mentioned earlier. The $\mathrm{OH}$ terminated surface reacts with the successive PDMAT exposure, producing $\mathrm{N}$ free $\mathrm{Ta}_{2} \mathrm{O}_{5}$. For this case, the saturation coverage of PDMAT molecules is largely dependent on the $\mathrm{OH}$-surface concentration, resulting in the growth rate vs temperature data shown in Fig. 3. Also, for O plasma, the ligands seem to remain almost intact, since nitrogen and carbon incorporation in the film is minimal. However, at high 
temperature growth, the PDMAT seems to decompose spontaneously. The previous report on CVD of $\mathrm{Ta}_{2} \mathrm{O}_{5}$ from PDMAT indicate that the PDMAT deposited Ta-N-C by selfdecomposition without any reactant at $400{ }^{\circ} \mathrm{C} .{ }^{5}$ Thus, at $T_{s}$ $=500{ }^{\circ} \mathrm{C}$, the self-decomposed PDMAT produce $\mathrm{N}$ incorporation forming TaN crystal in the films. Since our data show very small carbon incorporation even at this high temperature growth, we can conclude that even if some of the $\mathrm{C}$ is bonded to surface during $\mathrm{O}$ plasma exposure step by dissociation of alkylamide ligands, the highly reactive atomic oxygen effectively prevents carbon incorporation.

One possible explanation for the difference in carbon and nitrogen incorporation during PE-ALD of Ta oxide and nitride can be found in the differences in bonding strength. The bonding energy of $\mathrm{Ta}-\mathrm{H}$ is about $16.3 \mathrm{~kJ} / \mathrm{mol}$, while those of Ta-O and Ta-N are about 805 and $611 \mathrm{~kJ} / \mathrm{mol}^{36}$ So when the surface Ta atom is bonded to alkylamide ligands after PDMAT exposure step, the Ta-N bond may not be easily broken by $\mathrm{H}$ atom, due to very small bonding strength of $\mathrm{Ta}-\mathrm{H}$. Instead, atomic $\mathrm{H}$ could break the $\mathrm{N}-\mathrm{C}$ bond in the ligands leading to $\mathrm{C}$ incorporation by forming a $\mathrm{Ta}-\mathrm{C}$ bond with surface Ta atoms. In contrast, $\mathrm{O}$ plasma has much better chance to break the Ta-N bond to form a stronger Ta-O bond, resulting in more facile $\mathrm{N}$ removal. However, more detailed quantitative study on alkylamide precursor reactions with $\mathrm{H}$ or $\mathrm{O}$ (or $\mathrm{NH}_{3}$ and $\mathrm{H}_{2} \mathrm{O}$ ) would be required. Anyhow, the PDMAT precursor seems promising forming quite pure $\mathrm{Ta}_{2} \mathrm{O}_{5}$ either by thermal and PE-ALD. In contrast, considerable impurity incorporation for TaN ALD is resulted from PDMAT precursor, which may be problematic in some specific device applications.

\section{CONCLUSION}

The thermal and PE-ALD of Ta-based materials, $\mathrm{Ta}_{2} \mathrm{O}_{5}$ and $\mathrm{TaN}$, from alkylamide precursor were investigated. While pure $\mathrm{Ta}_{2} \mathrm{O}_{5}$ films were deposited from water or $\mathrm{O}$ plasma as a reactant, considerable incorporation of impurity was observed for TaN. Based upon the comparative studies, differences in growth mechanism were discussed. The alkylamide precursors should be considered as one of promising precursors for $\mathrm{Ta}_{2} \mathrm{O}_{5}$ ALD.

\section{ACKNOWLEDGMENTS}

This work was supported by Korea Research Foundation Grant funded by Korea Government (MOEHRD, Basic Research Promotion Fund) (KRF-2005-003-D00144 and KRF2006-311-D00114). The authors are deeply thankful to Professor Wang Chul Zin and his co-workers at POSTECH for their contributions in measuring film thickness by ellipsometry. The RBS analysis was performed at Korea Institute of Science and Technology.
${ }^{1}$ K. Holloway, P. M. Fryer, C. Cabral, Jr., J. M. E. Haper, P. J. Bailey, and K. H. Kelleher, J. Appl. Phys. 71, 5433 (1992).

${ }^{2}$ X. Yu, C. Zhu, M. F. Li, A. Chin, M. B. Yu, and D. L. Kwong, IEEE Electron Device Lett. 25, 501 (2004).

${ }^{3}$ G. D. Wilk, R. M. Wallace, and J. M. Anthony, J. Appl. Phys. 89, 5243 (2001).

${ }^{4}$ G. B. Alers, D. J. Werder, Y. Chabal, H. C. Lu, E. P. Gusev, E. Garfunkel, T. Gustafsson, and R. S. Urdahl, Appl. Phys. Lett. 73, 1517 (1998).

${ }^{5}$ K. A. Son, A. Y. Mao, Y. M. Sun, B. Y. Kim, F. Liu, A. Kamath, J. M. White, D. L. Gwong, D. A. Roberts, and R. N. Vrtis, Appl. Phys. Lett. 72, 1187 (1998).

${ }^{6}$ W. Zeng, E. Eisenbraun, H. Frisch, J. J. Sullivan, A. E. Kaloyeros, J. Margalit, and K. Beckd, J. Electrochem. Soc. 151, F172 (2004).

${ }^{7}$ S. Boughaba, M. Islam, J. P. McCaffrey, G. I. Sprouele, and M. J. Graham, Thin Solid Films 371, 119 (2000).

${ }^{8}$ M. Leskela and M. Ritala, Angew. Chem., Int. Ed. 42, 5548 (2003).

${ }^{9}$ H. Kim, J. Vac. Sci. Technol. B 21, 2231 (2003).

${ }^{10}$ K. Kukli, M. Leskela, and M. Ritala, Chem. Mater. 12, 1914 (2000).

${ }^{11}$ J. Sundqvist, H. Hogberg, and A. Harsta, Chem. Vap. Deposition 9, 245 (2003).

${ }^{12}$ C. W. Hill, G. J. Derderian, and G. Sanju, J. Electrochem. Soc. 152, G386 (2005).

${ }^{13}$ D. M. Hausmnn, P. Rouffignac, A. Smith, R. Gordon, and D. Monsma, Thin Solid Films 443, 1 (2003).

${ }^{14}$ K. E. Ellers, J. Winkler, K. Weeks, and S. Markus, J. Electrochem. Soc. 152, G589 (2005).

${ }^{15}$ H. Kim, C. Detavenier, O. Van der Straten, S. M. Rossnagel, A. J. Kellock, and D. G. Park, J. Appl. Phys. 98, 014308 (2005).

${ }^{16}$ J. W. Elam, M. Schuisky, J. D. Ferguson, and S. M. Gorge, Thin Solid Films 436, 145 (2003)

${ }^{17}$ J. J. Park, W. J. Lee, G. H. Lee, I. S. Kim, B. C. Shin, and S. G. Yoon, Integr. Ferroelectr. 68, 129 (2004).

${ }^{18}$ J. S. Becker, E. Kim, and R. G. Gordon, Chem. Mater. 16, 3497 (2004).

${ }^{19}$ W. J. Maeng and H. Kim, Electrochem. Solid-State Lett. 9, G191 (2006).

${ }^{20}$ K.-A. Son, A. Y. Mao, B. Y. Kim, F. Liu, E. D. Pylant, D. A. Hess, J. M. White, D. L. Kwong, D. A. Roberts, and R. N. Vrtis, J. Vac. Sci. Technol. A 16, 1670 (1998).

${ }^{21}$ J. C. Kwak, Y. H. Lee, and B. H. Choi, Appl. Surf. Sci. 230, 249 (2004).

${ }^{22}$ Y. Masuda, S. Wakamatsu, and K. Koumoto, J. Eur. Ceram. Soc. 24, 301 (2004).

${ }^{23}$ K. Kukli, M. Ritala, R. Matero, and M. Leskela, J. Cryst. Growth 212, 459 (2000).

${ }^{24}$ H. Kim, C. Lavoie, M. Copel, V. Narayanan, D. G. Park, and S. M. Rossnagel, J. Appl. Phys. 95, 5348 (2004).

${ }^{25}$ J. Kim, S. Kim, H. Jeon, M.-H. Cho, K.-B. Chung, and C. Bae, Appl. Phys. Lett. 87, 053108 (2005).

${ }^{26}$ X. Zhao, N. P. Magatoto, and J. A. Kelber, Thin Solid Films 478, 188 (2005).

${ }^{27}$ Z. Wang, H. Sakaue, S. Shingubara, and T. Takahagi, Jpn. J. Appl. Phys., Part 1 42, 1843 (2003)

${ }^{28}$ Y. Y. Wu, A. Kohn, and M. Eizenberg, J. Appl. Phys. 95, 6167 (2004).

${ }^{29}$ C. H. Han, K. N. Cho, J. E. Oh, S. H. Paek, C. S. Park, S. I. Lee, M. Y. Lee, and J. G. Lee, Jpn. J. Appl. Phys., Part 1 37, 2646 (1998).

${ }^{30}$ X. Liu, S. Ramanathan, A. Longdergan, A. Sivastava, D. Lee, T. E. Siedel, J. T. Barton, D. Pang, and R. G. Gordon, J. Electrochem. Soc. 3, G213 (2005).

${ }^{31}$ K. Kukli, M. Ritala, T. Sajavara, J. Keinonen, and M. Leskela, Chem. Vap. Deposition 8, 199 (2002).

${ }^{32}$ S. J. Yun, J. W. Lim, and J. H. Lee, Electrochem. Solid-State Lett. 7, F81 (2004).

${ }^{33}$ R. Puurunen, Chem. Vap. Deposition 9, 327 (2003)

${ }^{34}$ J. Aarik, A. Aidla, V. Sammelselg, H. Siimon, and T. Uustare, J. Cryst. Growth 169, 496 (1996).

${ }^{35}$ S. X. Lao, R. M. Martin, and J. P. Chang, J. Vac. Sci. Technol. A 23, 488 (2005).

${ }^{36}$ J. A. Dean, Lange's Handbook of Chemistry, 15th ed. (McGraw-Hill, New York, 2001). 